\title{
Social-Cognitive Predictors of Physical Exercise Adherence: Three Longitudinal Studies in Rehabilitation
}

\author{
Ralf Schwarzer \\ Free University of Berlin \\ Jochen P. Ziegelmann \\ Free University of Berlin
}

\author{
Aleksandra Luszczynska \\ University of Sussex and Warsaw School of \\ Social Psychology
}

Urte Scholz

University of Zurich

\author{
Sonia Lippke \\ Free University of Berlin
}

\begin{abstract}
Objective: Levels of physical exercise adherence are not predicted well by behavioral intentions. Therefore, action planning and recovery self-efficacy were specified as proximal predictors to bridge the gap between intentions and adherence. The prediction model was examined in 3 studies with participants who were enrolled in cardiac rehabilitation (Study 1, $N=353$; Study $2, N=114$ ) or orthopedic rehabilitation (Study 3, $N=368$ ). Main Outcome Measure: Each study included 3 measurement points in time, covering a period between 4 and 12 months. Intentions, plamning, self-efficacy, and exercise levels were assessed. Results: Structural equation modeling revealed that 1 common model fit all 3 data sets well. Results differed in terms of variance accounted for, but the overall patterns of estimated parameters were similar. Conclusions: Although health risk perception appeared to be a negligible factor, action planning and recovery self-efficacy were effective predictors of physical exercise adherence.
\end{abstract}

Keywords: exercise, rehabilitation, self-efficacy, planning, adherence, health behavior theory

\begin{abstract}
Most health behavior theories assume that a person's behavior is the outcome of a conscious intention (e.g., "I intend to run four times a week for at least 30 minutes each time."). Intention forming is seen as being determined by beliefs and attitudes. Therefore, the focus of health behavior models has been on identifying a parsimonious set of predictors that included constructs such as perceived barriers, social norms, disease severity, personal vulnerability, perceived self-efficacy, and so forth. These are then combined into a single prediction equation for explaining behavioral intention and behavior change. The most prominent approaches are the Theory of Reasoned Action (Fishbein \& Ajzen, 1975), Theory of Planned Behavior (Ajzen, 1991), and Protection Motivation Theory (Maddux \& Rogers, 1983; for an overview and critique of these and other models, see Abraham \& Sheeran, 2000; Armitage \& Conner, 2000, 2001; Rutter \& Quine, 2002; Schwarzer, 1992; Sutton, 1998; Weinstein, 1993, 2007). However, it is quite common that people do not behave in accordance with
\end{abstract}

Ralf Schwarzer and Jochen P. Ziegelmann, Department of Psychology, Free University of Berlin; Aleksandra Luszczynska, Department of Psychology, University of Sussex and Warsaw School of Social Psychology; Urte Scholz, Department of Psychology, University of Zurich; and Sonia Lippke, Department of Psychology, Free University of Berlin.

Correspondence concerning this article should be addressed to Ralf Schwarzer, Gesundheitspsychologie 10, Freie Universität Berlin, Habelschwerdter Allee 45, 14195, Berlin, Germany. E-mail: health@zedat.fuberlin.de their intentions. For example, unforeseen barriers emerge, and people give in to temptations. In a postintentional phase, various factors can compromise or facilitate the translation of intentions into action. Some of these postintentional factors have been studied, such as perceived self-efficacy (Luszczynska \& Schwarzer, 2003; Scholz, Sniehotta, \& Schwarzer, 2005) and action planning (Lippke, Ziegelmann, \& Schwarzer, 2004; Luszczynska, 2006; Luszczynska, Sobczyk, \& Abraham, 2007; Sniehotta, Scholz, \& Schwarzer, 2005; Ziegelmann, Lippke, \& Schwarzer, 2006). The three studies presented here examine the role that these two factors, self-efficacy and action planning, play in the adherence to physical exercise in cardiac and orthopedic rehabilitation patients, based on three samples from two countries.

\section{A Social-Cognitive Prediction Model for Physical Exercise Adherence}

The Health Action Process Approach (HAPA; Lippke et al., 2004; Luszczynska \& Schwarzer, 2003; Sniehotta et al., 2005; Ziegelmann et al., 2006) extends previous models into a process model that also includes postintentional factors. HAPA is based on social-cognitive theory (Bandura, 1986) and Heckhausen's (1991) volition theory. It was designed as an alternative to the Theory of Reasoned Action, the Theory of Planned Behavior, and Protection Motivation Theory, none of which includes volitional factors.

The HAPA model suggests a distinction between (a) preintentional motivation processes that lead to a behavioral intention, and (b) postintentional volition processes that lead to the actual health 
behavior. Within both phases, different patterns of social-cognitive predictors may emerge. In the initial motivation phase, a person develops an intention to act. In this phase, risk perception is seen as a distal antecedent ("I am at risk for cardiovascular disease"). Risk perception in itself is insufficient to enable a person to form an intention. Rather, it sets the stage for a contemplation process and further elaboration about consequences and competencies. Similarly, positive outcome expectancies ("If I exercise five times per week, I will reduce my cardiovascular risk") are chiefly seen as being important in the motivation phase, when a person balances the pros and cons of certain behavioral outcomes. Furthermore, one needs to believe in being able to perform a desired action (perceived self-efficacy: "I am capable of adhering to my exercise schedule in spite of the temptation to watch TV').

Perceived self-efficacy operates in concert with positive outcome expectancies, both of which contribute substantially to forming an intention. Both beliefs are necessary for forming intentions to adopt difficult behaviors, such as regular physical exercise. After a person develops an inclination towards a particular health behavior, the "good intention" has to be transformed into detailed instructions on how to perform the desired action. Once an action has been initiated, it has to be maintained. This is not achieved through a single act of will, but involves self-regulatory skills and strategies. Among these proximal factors in the postintentional phase are action planning and recovery self-efficacy. The action planning factor (implementation intention) was suggested by Heckhausen (1991) and Gollwitzer (1993), and recovery selfefficacy by Marlatt, Baer, and Quigley (1995; see below). Most social cognition models do not address postintentional factors. Bandura (1997) described in detail pre- and postintentional processes, but did not explicitly depict a postintentional factor in a diagram of his model (Bandura, 2000, p. 121). In the following, these two volitional constructs will be explained in more detail.

\section{Phase-Specific Self-Efficacy Beliefs as a Volitional Mediator for Physical Exercise}

Perceived self-efficacy has been found to be important for all stages in the health behavior change process (Bandura, 1997), but it does not always constitute exactly the same construct. Its meaning depends on the particular situation of individuals who may be more or less advanced in the change process. The distinction between action self-efficacy and recovery self-efficacy has been brought up by Marlatt et al. (1995) in the domain of addictive behaviors. The rationale for the distinction between several phasespecific self-efficacy beliefs is that during the course of health behavior change, different tasks have to be mastered, and that different self-efficacy beliefs are required for successful mastery of these tasks. For example, a person might be confident in his or her capability to be physically active in general (i.e., high action self-efficacy), but might not be very confident to resume physical activity after a setback (i.e., low recovery self-efficacy). Action self-efficacy refers to the first phase of the process, in which an individual does not yet act, but develops a motivation to do so.

Recovery self-efficacy addresses the experience of failure and recovery from setbacks. If a lapse occurs, individuals can fall prey to the "abstinence violation effect," that is, they attribute their lapse to internal, stable, and global causes, dramatize the event, and interpret it as a full-blown relapse (Marlatt et al., 1995). High self-efficacious individuals, however, avoid this effect by attributing the lapse to an external high-risk situation and by finding ways to control the damage and to restore hope. Recovery self-efficacy pertains to one's conviction to get back on track after being derailed. The person trusts his/her competence to regain control after a setback or failure and to reduce harm. There is a functional difference between the two self-efficacy constructs, whereas the temporal sequence is less important. Different phase-specific selfefficacy beliefs may be harbored at the same point in time. The assumption is that they operate in a different manner. For example, recovery self-efficacy is most functional when it comes to resuming an interrupted chain of action, whereas action self-efficacy is most functional when facing a challenging demand.

This distinction between phase-specific self-efficacy beliefs has proven useful in several domains of behavior change (see Marlatt et al., 1995). Other authors (Rodgers, Hall, Blanchard, McAuley, \& Munroe, 2002; Rodgers \& Sullivan, 2001) have found evidence for phase-specific self-efficacy beliefs in the domain of exercise behavior (i.e., task self-efficacy, coping self-efficacy, and scheduling self-efficacy). In studies applying the HAPA model, phasespecific self-efficacy differed in the effects on various preventive health behaviors, such as breast self-examination (Luszczynska \& Schwarzer, 2003), dietary behaviors (Schwarzer \& Renner, 2000), physical exercise (Scholz et al., 2005), and dental flossing (Schüz, Sniehotta, \& Schwarzer, 2007).

\section{Planning as a Volitional Mediator for Physical Exercise}

Good intentions are more likely to be translated into action when people develop success scenarios and preparatory strategies of approaching a difficult task. Mental simulation helps to identify cues for action. The terms planning and implementation intentions have been used to address this phenomenon. Research on action plans has been suggested by Leventhal, Singer, and Jones (1965), who stated that fear appeals can facilitate health behavior change only when combined with specific instructions on when, where, and how to perform them. Renewed attention to planning emerged when the concept of implementation intentions was introduced (Gollwitzer, 1999), which is a refined concept of action planning.

Three meta-analyses have summarized the findings on the effects of implementation intentions on health behaviors (for an overview, see Sheeran, Milne, Webb, \& Gollwitzer, 2005). Selfreported planning was also found to mediate the relations between intentions and physical activity among students (Conner \& Norman, 2005). Planning is more than simply an extension of the intention because it includes situation parameters (when, where) and a sequence of action (how). It is more effective than intentions when it comes to the likelihood and speed of performance, mainly because the behavior is being elicited almost automatically when the relevant situational cues are encountered. People do not forget their intentions easily when specified in a when, where, and how manner (for an overview and meta-analysis, see Gollwitzer \& Sheeran, 2006). Therefore, the general emphasis of the present three studies lies on the assumption that action plans constitute a valuable proximal construct by moving further into the volition phase, and by allowing a better prediction of behaviors (Scholz, Sniehotta, Burkert, \& Schwarzer, in press; Ziegelmann, Luszczynska, Lippke, \& Schwarzer, 2007). 


\section{General Aims of the Three Studies}

In general, the aim of the article is to examine the validity of the HAPA model for the special case of physical exercise adherence in rehabilitation patients. The model used in the following three studies includes three predictors of the intention to exercise (action self-efficacy, outcome expectancies, risk perception) and three predictors of the behavior (intention, recovery self-efficacy, planning). It is to be examined whether the model holds across diverse samples, measures, and research designs. The present study differs from previous ones mainly because it considers two mediators simultaneously, namely recovery self-efficacy and planning. This pattern of variables has not been examined jointly so far in the context of physical exercise. Two research questions have been posed: (a) Does a structural equation model, specified in terms of the HAPA, fit the data in all three studies? and (b) Do the two postintentional constructs, that is, planning and recovery selfefficacy, account for variance in self-reported physical exercise?

\section{Data Analysis}

Path analysis with maximum likelihood estimation was employed (see Arbuckle, 2003) to examine the longitudinal associations between HAPA variables. In the hypothesized model, perceived risk, outcome expectancies, and action self-efficacy were specified as predictors of intention. Action self-efficacy was specified as a predictor of recovery self-efficacy. Intention and recovery self-efficacy were specified as predictors of planning. Finally, planning and recovery self-efficacy were specified as predictors of behavior. Evaluation of model-data fit was based on the following indices: Tucker-Lewis index (TLI), comparative fit index (CFI), root mean square error of approximation (RMSEA), standardized root mean square residual (SRMR), and $\chi^{2}$ divided by degrees of freedom $\left(\chi^{2} / \mathrm{df}\right)$. The following values indicate a good fit of the model to the data: TLI and CFI to range from .90 to 1, RMSEA and SRMR below .09 , and $x^{2} / \mathrm{df}$ between 1 and 2 (see Hu \& Bentler, 1995).

\section{Study 1: Predicting Physical Exercise Adherence After Cardiac Rehabilitation Over a Time Span of 4 Months}

The first study examines exercise adherence in a sample of cardiac rehabilitation patients in Germany. The study had a number of different aims that are presented elsewhere (Scholz et al., 2005; Sniehotta et al., 2005). The following analysis applies the HAPA model to a longitudinal data set with three points in time, covering a 4-month period. The questions are whether the model fit the data, and whether the two postintentional factors, recovery self-efficacy and planning, account for variance in behavior.

\section{Method}

Participants. Overall, 484 persons who participated in a 3-week inpatient rehabilitation program agreed to take part in the study. The second and third measurement points in time ( 2 months and 4 months after discharge) were completed by 395 and 353 persons, respectively. Dropout analyses in terms of sex, $\chi^{2}(1, N=$ $484)=0.43, n s ;$ and age, $F(1,432)=1.35, n s ;$ showed no significant differences between the participants in the initial sample and those who completed all three waves of data collection.
However, dropouts reported slightly lower behavioral intentions, $F(1,483)=8.33, p<.05$; and action self-efficacy, $F(1,483)=$ $6.26, p<.05$; than persons who continued their participation. Mean age of participants was $58.8, S D=9.96$, with the youngest participant being 31 years old and the oldest 82 years old. Men constituted $79 \%$ of the sample. About half of the participants were currently employed.

Procedure. All participants received information about the purpose and content of the study, and they gave informed consent about voluntary participation. Time 1 took place during the second week of the 3-week stay in the rehabilitation center. Time 2 and Time 3 questionnaires were sent together with a stamped return envelope to the participant at home 2 and 4 months after discharge. In Germany, cardiac rehabilitation is usually provided on an inpatient basis and consists of a comprehensive physical and psychoeducational training, including regular sessions of physical exercise on an almost daily basis.

Measures. Baseline physical activity, risk perception, positive outcome expectancies, action self-efficacy, and behavioral intentions were assessed at the first measurement point in time (Time 1), planning and recovery self-efficacy were assessed at Time 2 , and physical activity at Time 3. All psychometric scales were adapted from Sniehotta et al. (2005) and Scholz et al. (2005). Physical activity was assessed with a subset of the International Physical Activity Questionnaire (Booth, 2000) because this subset constituted the best match with the exercise recommendations of the rehabilitation clinic. For item examples, means, standard deviations, and internal consistencies, see Table 1. For intercorrelations between all variables see Table 2 .

\section{Results}

The hypothesized model fit the data (see Table 3). Figure 1 displays the parameter estimates (standardized solution). Planning and self-efficacy emerged as mediators, as hypothesized. Nine percent of variance of the recovery self-efficacy has been accounted for by action self-efficacy, attesting to the discriminant validity of the two constructs. Of the planning variance, $17 \%$ has been accounted for by intention and recovery self-efficacy, and $14 \%$ of the physical activity variance has been explained jointly by planning and recovery self-efficacy. Inclusion of past behavior in the model (see Tables 3 and 4) did not make a substantial difference in terms of model fit and structural coefficients.

\section{Study 2: Predicting Physical Exercise Adherence After} Cardiac Rehabilitation Over a Time Span of 8 Months

The second study examines exercise adherence in a sample of cardiac rehabilitation patients in Poland. The study had a number of different aims that are presented elsewhere (see Luszczynska, 2006; Luszczynska \& Sutton, 2006). The following analysis applies the HAPA model to a longitudinal data set with three measurement points in time, covering an 8-month period. The current research examines whether the hypothesized model fits the data, and whether self-efficacy and planning account for a substantial amount of variance in subsequent behavior.

\section{Method}

Participants. One hundred and thirty individuals who had experienced an uncomplicated myocardial infarction (MI) were 
Table 1

Overview of Variables and Psychometric Data of the Three Studies

\begin{tabular}{|c|c|c|c|c|c|c|c|c|}
\hline Construct & Study & Item example & $\begin{array}{l}\text { No. of } \\
\text { items }\end{array}$ & Response scale & $\alpha$ & $M$ & $S D$ & $\begin{array}{l}\text { Factor } \\
\text { loadings }\end{array}$ \\
\hline \multirow[t]{3}{*}{$\begin{array}{l}\text { Risk } \\
\text { perception }\end{array}$} & 1 & $\begin{array}{l}\text { If I keep my lifestyle the way it was prior to the acute } \\
\text { treatment, I will suffer from coronary health problems. }\end{array}$ & 3 & 1 to $4^{a}$ & .89 & 3.10 & 0.83 & .83 to .87 \\
\hline & 2 & $\begin{array}{l}\text { Compared to other persons of your age and sex, how do } \\
\text { you estimate the likelibood that you will ever develop } \\
\text { other cardiovascular diseases? }\end{array}$ & 3 & $\begin{array}{l}-3 \text { (much below average) } \\
\text { to }+3 \text { (much above } \\
\text { average) }\end{array}$ & .81 & -0.13 & 1.45 & .61 to .82 \\
\hline & 3 & $\begin{array}{l}\text { Compared to other persons of your age and sex, how do } \\
\text { you estimate the likelihood that you will ever suffer } \\
\text { from chronic pain? }\end{array}$ & 3 & $\begin{array}{l}\text { I (much below average) } \\
\text { to } 5 \text { (much above } \\
\text { average) }\end{array}$ & .85 & 2.96 & 0.86 & .62 to .92 \\
\hline \multirow[t]{3}{*}{$\begin{array}{l}\text { Outcome } \\
\text { expectancies }\end{array}$} & 1 & $\begin{array}{l}\text { If I would exercise on a regular basis, then I would feel } \\
\text { balanced in my daily life. }\end{array}$ & 3 & 1 to $4^{a}$ & .70 & 3.6 & 0.50 & .63 to .71 \\
\hline & 2 & $\begin{array}{l}\text { If I would adopt regular exercise, my family would be } \\
\text { satisfied. }\end{array}$ & 4 & 1 to $4^{\text {at }}$ & .86 & 3.55 & 0.70 & .62 to .91 \\
\hline & 3 & $\begin{array}{l}\text { If I would engage in physical exercise on } 2 \text { or more days } \\
\text { per week, for at least } 20 \text { minutes each time, then I } \\
\text { would be doing something good for my health. }\end{array}$ & 6 & 1 to $4^{a}$ & .73 & 3.19 & 0.52 & .48 to .84 \\
\hline \multirow[t]{3}{*}{ Intention } & 1 & I intend to become physically active on a regular basis. & 4 & 1 to $4^{x}$ & .76 & 3.35 & 0.61 & .55 to .76 \\
\hline & 2 & $\begin{array}{l}\text { Within } 6 \text { months after the rehabilitation, do you intend to } \\
\text { follow the exercise recommendations? }\end{array}$ & 3 & 1 to $4^{a}$ & .74 & 2.82 & 0.65 & .58 to .77 \\
\hline & 3 & $\begin{array}{l}\text { I intend to exercise for } 20 \text { minutes or more on at least } 2 \\
\text { days per week on a regular basis. }\end{array}$ & 5 & 1 to $4^{\mathrm{a}}$ & .63 & 3.40 & 0.64 & .66 to .84 \\
\hline \multirow[t]{3}{*}{$\begin{array}{l}\text { Action self- } \\
\text { efficacy }\end{array}$} & 1 & $\begin{array}{l}\text { I am confident that I can adjust myself to a physically } \\
\text { active lifestyle. }\end{array}$ & 3 & 1 to $4^{*}$ & .75 & 3.23 & 0.65 & .50 to .74 \\
\hline & 2 & $\begin{array}{l}\text { I am confident that I am able to initiate recommended } \\
\text { exercises even if I would have to mobilize myself to } \\
\text { start doing them at once. }\end{array}$ & 3 & 1 to $4^{4}$ & .93 & 3.06 & 0.86 & .85 to .91 \\
\hline & 3 & $\begin{array}{l}\text { I am confident that I can be physically active at least } \\
\text { twice per week for at least } 20 \text { minutes. }\end{array}$ & 3 & 1 to $4^{\mathrm{a}}$ & .61 & 3.28 & 0.63 & .44 to .62 \\
\hline \multirow[t]{3}{*}{ Planning } & 1 & I have my own plan regarding when to exercise. & 4 & 1 to $4^{\mathrm{a}}$ & .94 & 3.21 & 0.89 & .86 to .92 \\
\hline & 2 & I have my own plan regarding how often to exercise. & 3 & 1 to $4^{x}$ & .90 & 2.80 & 0.95 & .68 to .97 \\
\hline & 3 & $\begin{array}{l}\text { I have planned precisely when to perform my physical } \\
\text { activities. }\end{array}$ & 9 & 1 to $4^{\text {a }}$ & .93 & 3.27 & 0.74 & .66 to .90 \\
\hline \multirow[t]{3}{*}{$\begin{array}{l}\text { Recovery } \\
\text { self-efficacy }\end{array}$} & 1 & $\begin{array}{l}\text { I am confident that I can resume a physically active } \\
\text { lifestyle, even if I have relapsed several times. }\end{array}$ & 3 & 1 to $4^{a}$ & .92 & 3.21 & 0.82 & .86 to .93 \\
\hline & 2 & $\begin{array}{l}\text { I am confident that I am able to resume my regular } \\
\text { exercises after failures to pull myself together. }\end{array}$ & 3 & 1 to $4^{\text {a }}$ & .85 & 2.21 & 1.03 & .79 to .86 \\
\hline & 3 & $\begin{array}{l}\text { I am confident that I can resume my physical activity, } \\
\text { even when feeling weak after an illness. }\end{array}$ & 6 & 1 to $4^{4}$ & .92 & 3.06 & 0.81 & .94 to .96 \\
\hline \multirow[t]{3}{*}{$\begin{array}{l}\text { Exercise } \\
\text { behavior }\end{array}$} & 1 & $\begin{array}{l}\text { Within the last } 4 \text { weeks, how often per week did you } \\
\text { engage on average in vigorous exercise (e.g., } \\
\text { swimming, running, walking, biking) that was as } \\
\text { intense as in your rehab program? }\end{array}$ & 2 & 0 to 14 & .67 & 2.54 & 2.05 & .60 to .81 \\
\hline & 2 & $\begin{array}{l}\text { Within the last } 2 \text { weeks, how often did you engage (for } \\
\text { at least } 30 \text { minutes) in any kind of moderate physical } \\
\text { activity (e.g., walking, cycling on level terrain, } \\
\text { swimming)? }\end{array}$ & 3 & 0 to $10^{b}$ & .60 & 2.65 & 1.35 & .50 to .79 \\
\hline & 3 & $\begin{array}{l}\text { In the last } 6 \text { months, how often have you managed to be } \\
\text { physically active at least } 20 \text { minutes per week on } 2 \text { or } \\
\text { more days? }\end{array}$ & 2 & 1 (never) to 6 (always) & .66 & 3.68 & 1.07 & .59 to .65 \\
\hline \multirow[t]{3}{*}{$\begin{array}{l}\text { Baseline } \\
\text { exercise } \\
\text { behavior }\end{array}$} & 1 & $\begin{array}{l}\text { How often per week did you engage on average in } \\
\text { vigorous exercise (e.g., swimming, running, walking, } \\
\text { biking) during the last months before your acute } \\
\text { treatment? }\end{array}$ & 1 & 0 to 14 & - & .37 & .61 & - \\
\hline & 2 & $\begin{array}{l}\text { Within } 2 \text { weeks prior to MI, how often did you engage } \\
\text { (for at least } 30 \text { minutes) in any kind of moderate } \\
\text { physical activity (e.g., walking, cycling on a level } \\
\text { terrain, swimming)? }\end{array}$ & 3 & 0 to $10^{\mathrm{b}}$ & .65 & 1.90 & 1.44 & .46 to .80 \\
\hline & 3 & $\begin{array}{l}\text { In the last } 6 \text { months prior to rehabilitation, how often } \\
\text { have you managed to be physically active at least } 20 \\
\text { minutes per week on } 2 \text { or more days? }\end{array}$ & 2 & 1 (never) to 6 (always) & .64 & 3.21 & 1.19 & .56 to .82 \\
\hline
\end{tabular}

Note. Study 1: Patients enrolled in cardiac rehabilitation (German); Study 2: Patients enrolled in cardiac rehabilitation (Polish); Study 3: Patients enrolled in orthopedic rehabilitation (German). MI = myocardial infarction.

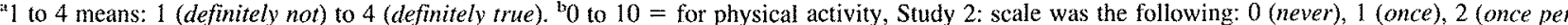
week), 4 (twice per week), 6 (three times per week), 8 (four times per week), 10 (five or more times per week); for Study 1 the response format was open. 
Table 2

Correlations Between the Social-Cognitive Variables and Behavior Within the Three Samples

\begin{tabular}{|c|c|c|c|c|c|c|c|}
\hline Variable study & $\begin{array}{c}\text { Outcome } \\
\text { expectancies }\end{array}$ & $\begin{array}{c}\text { Action } \\
\text { self-efficacy }\end{array}$ & Intention & Planning & $\begin{array}{c}\text { Recovery } \\
\text { self-efficacy }\end{array}$ & $\begin{array}{l}\text { Baseline } \\
\text { behavior }\end{array}$ & $\begin{array}{l}\text { Behavior } \\
\text { at Time } 3\end{array}$ \\
\hline \multicolumn{8}{|l|}{ Risk perception } \\
\hline 1 & $.20^{20}$ & -.05 & $.10^{*}$ & .03 & .05 & $-.16^{* *}$ & -.08 \\
\hline 2 & .05 & .12 & .14 & $.23^{*}$ & .10 & .01 & $.30^{\circ}$ \\
\hline 3 & -.08 & $-.15^{* *}$ & -.03 & -.07 & -.09 & $-.15^{* 2}$ & -.19 \\
\hline \multicolumn{8}{|c|}{ Outcome expectancies } \\
\hline 1 & & $.32^{* *}$ & $.40^{* *}$ & $.20^{* *}$ & $.19^{* *}$ & $.11^{*}$ & $.15^{\circ}$ \\
\hline 2 & & $.44^{* *}$ & $.27^{* *}$ & .10 & .09 & .14 & .03 \\
\hline 3 & & $.33^{* *}$ & $.19^{* * *}$ & $.21^{* * *}$ & .06 & .03 & .05 \\
\hline \multicolumn{8}{|l|}{ Action self-efficacy } \\
\hline 1 & & & $.59^{* *}$ & $.29^{* *}$ & $.30^{* *}$ & $.32^{38}$ & $.17^{\circ *}$ \\
\hline 2 & & & $.28^{* *}$ & $.29^{* * *}$ & $.27^{*}$ & .27 & $.24_{v x}^{*}$ \\
\hline 3 & & & $.26^{* *}$ & $.30^{* *}$ & $.19^{* *}$ & $.26^{* *}$ & $.30^{\mathrm{vx}}$ \\
\hline \multicolumn{8}{|l|}{ Intention } \\
\hline 1 & & & & $.31^{* *}$ & $.20^{* *}$ & .08 & $19 \%$ \\
\hline 2 & & & & $.33^{\min }$ & $.30^{* * *}$ & .30 & $32 \%$ \\
\hline 3 & & & & $.45^{* *}$ & $.26^{* *}$ & $.11^{*}$ & $39^{\circ 3}$ \\
\hline \multicolumn{8}{|l|}{ Planning } \\
\hline 1 & & & & & $.25^{* *}$ & -.05 & $.26 \%$ \\
\hline 2 & & & & & $.32^{\alpha *}$ & .20 & $.51^{\circ}$ \\
\hline 3 & & & & & $.42^{* *}$ & .09 & $.33^{* *}$ \\
\hline \multicolumn{8}{|c|}{ Recovery self-efficacy } \\
\hline 1 & & & & & & .05 & $.19 \%$ \\
\hline 2 & & & & & & .26 & $.50 \mathrm{~m}$ \\
\hline 3 & & & & & & $.15^{* *}$ & .30 \\
\hline
\end{tabular}

Note. Study 1: cardiac rehabilitation patients (German); Study 2: cardiac rehabilitation patients (Polish); Study 3: orthopedic rehabilitation patients (German).

${ }^{*} p<.05 .{ }^{* *} p<.01$

invited to take part in the study. One person refused, and 15 participants dropped out at the second or third wave of data collection. The final sample consisted of 114 participants, aged 39 to 67 years, $M=54.3, S D=6.9,64 \%$ of them being men. About $69 \%$ of respondents were married or living with a partner; $51 \%$ had completed high school education, and $21 \%$ had a university degree.

Table 3

Summary of Model Fit Indices for Three Studies (With and Without Controlling for Baseline Exercise)

\begin{tabular}{lccc}
\hline \multicolumn{1}{c}{ Fit indices } & Study 1 & Study 2 & Study 3 \\
\hline $\begin{array}{l}\text { Models without controlling for } \\
\text { the baseline exercise }\end{array}$ & & & \\
TLI & 0.97 & 0.98 & 0.88 \\
CFI & 0.98 & 0.97 & 0.92 \\
$\chi^{2} / d f$ & 1.43 & 1.61 & 2.92 \\
RMSEA & 0.03 & 0.04 & 0.07 \\
SRMR & 0.04 & 0.08 & 0.07 \\
Models with controlling for & & & \\
$\quad$ the baseline exercise & 0.97 & 0.96 & 0.98 \\
TLI & 0.98 & 0.96 & 0.99 \\
CFI & 1.41 & 1.78 & 3.02 \\
X $^{2} / d f$ & 0.03 & 0.07 & 0.07 \\
RMSEA & 0.04 & 0.08 & 0.06 \\
SRMR & & & \\
\hline
\end{tabular}

Note. TLI $=$ Tucker-Lewis index; $\mathrm{CFI}=$ comparative fit index; $x^{2} / d f=$ chi-square divided by degrees of freedom: $\cdot$ RMSEA $=$ root mean square error of approximation; SRMR = standardized root mean square residual.
To check the dropout, patients who discontinued participating in the study at Time 2 or Time 3 were compared with those who took part in all three waves. At Time 1, participants did not differ in age, $F(1,128)=0.89, n s ;$ gender, $\chi^{2}(1, N=130)=0.12, n s ;$ education, $F(1,127)=3.20, n s ; \mathrm{BMI}, F(1,127)=0.63$, ns; and total cholesterol, $F(1,128)=1.21$, ns. In addition, a comparison between those who participated in all waves and those who dropped out at Time 3 revealed no differences in risk perception, $F(1,128)=0.32, n s ;$ outcome expectancies, $F(1,129)=3.12, n s$; action self-efficacy, $F(1,128)=2.74, n s$; intention, $F(1,127)=$ $0.15, n s$; planning, $F(1,127)=0.52, n s$; and recovery selfefficacy, $F(1,127)=0.55, n s$.

Procedure. Participants were approached by members of the research team (psychologists or rehabilitation specialists), informed about the purpose and design of the study, and asked to participate on a voluntary basis. At all three measurement points, members of the research team assisted each patient individually. Time 1 took place 4 to 10 days after MI. Time 2 took place in the eighth week after MI ( 2 weeks after a short-term rehabilitation). Time 3 took place 8 months after MI. At Time 1, data were collected in five hospitals. Data collections at Times 2 and 3 took place in three cardiac rehabilitation centers; the research team members telephoned the participants and invited them to take part in the respective data collection wave.

The short-term (2-week) rehabilitation program consisted of cardiovascular training exercises of low frequency (once per day or less) and education regarding nutrition and nonsmoking. The program represents Phase 2 Cardiac Rehabilitation that follows Phase 1 , which is a hospitalization initially associated with a 


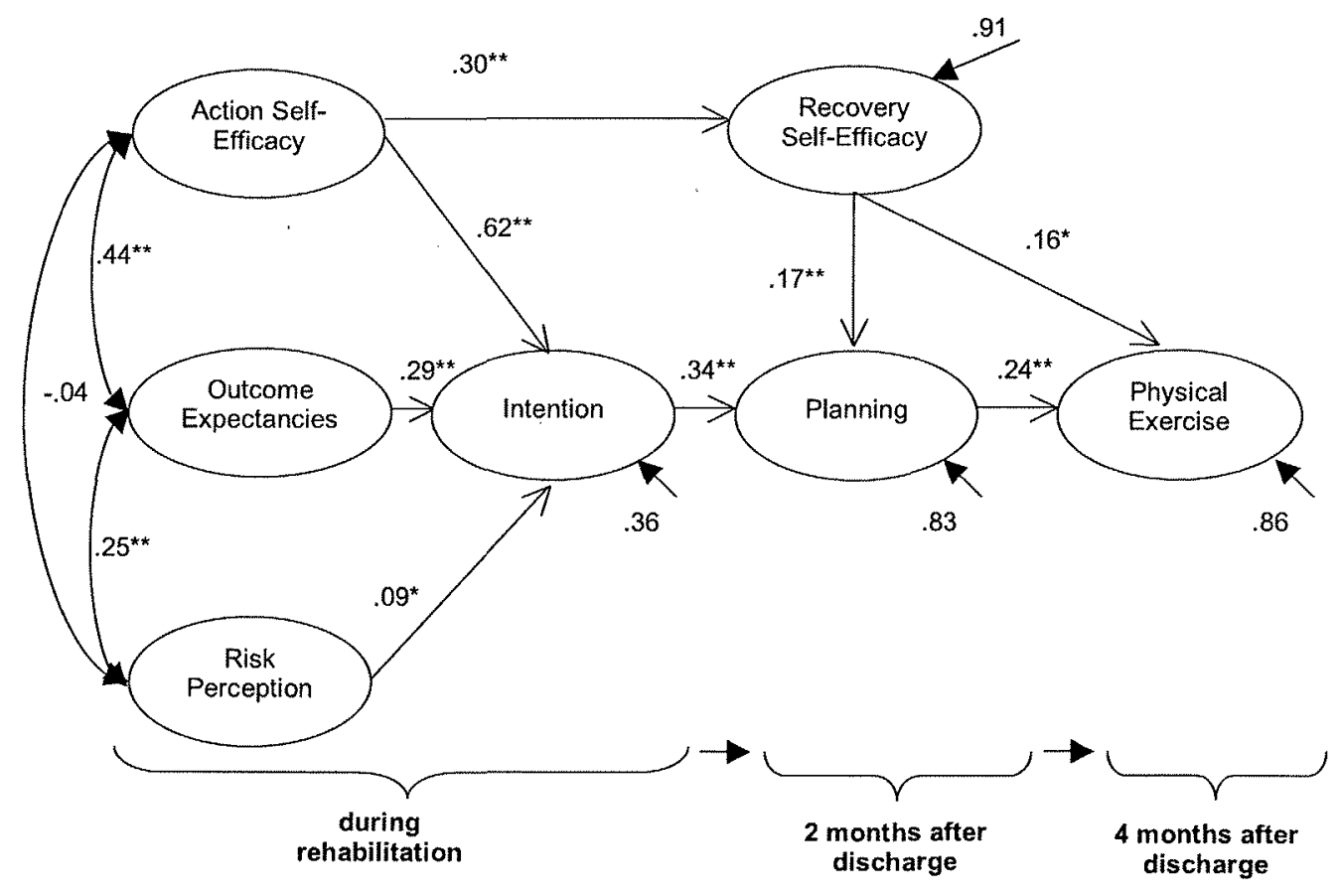

Figure 1. Prediction model for cardiac patients in Study $1(N=353) .{ }^{\dagger} p<.10 .{ }^{*} p<.05 .{ }^{*} p<.01$.

Table 4

Path and Correlation Coefficients for Models With Baseline Physical Activity Controlled

\begin{tabular}{|c|c|c|c|}
\hline $\begin{array}{c}\text { Coefficients for relations between study } \\
\text { variables/variance explained }\end{array}$ & $\begin{array}{c}\text { Study } \\
1\end{array}$ & $\begin{array}{c}\text { Study } \\
2\end{array}$ & $\begin{array}{c}\text { Study } \\
3\end{array}$ \\
\hline $\begin{array}{l}\text { Action self-efficacy and outcome } \\
\text { expectancies }\end{array}$ & $.42^{* * 4 * *}$ & $.49^{* * * * * * *}$ & $.50^{* * * * *}$ \\
\hline Action self-efficacy and risk perception & $.25^{* * * * *}$ & .11 & $-.23^{* *}$ \\
\hline $\begin{array}{l}\text { Outcome expectancies and risk } \\
\text { perception }\end{array}$ & -.01 & .04 & -.10 \\
\hline From action self-efficacy to intention & $.73^{* * *}$ & $.25^{*}$ & $.40^{* * *}$ \\
\hline $\begin{array}{l}\text { From outcome expectancies to } \\
\text { intention }\end{array}$ & $.22^{* * * *}$ & $.28^{\prime \prime}$ & .10 \\
\hline From risk perception to intention & .06 & $-.21^{*}$ & .02 \\
\hline $\begin{array}{l}\text { From action self-efficacy to recovery } \\
\text { self-efficacy }\end{array}$ & $.36^{* * *}$ & $.25^{*}$ & $.31^{* * *}$ \\
\hline From intention to planning & $.35^{* * *}$ & $.40^{* * *}$ & $.51^{* * *}$ \\
\hline From recovery self-efficacy to planning & $.16^{* *}$ & $.19^{*}$ & $.29^{* * * *}$ \\
\hline $\begin{array}{l}\text { From recovery self-efficacy to physical } \\
\text { exercise }\end{array}$ & $.14^{*}$ & $.45^{* *}$ & $.20^{* *}$ \\
\hline From planning to physical exercise & $.33^{* * *}$ & $.29^{*}$ & $.29^{* * * *}$ \\
\hline $\begin{array}{l}\text { From baseline exercise to physical } \\
\text { exercise }\end{array}$ & $.18^{* *}$ & $.22^{*}$ & $.35^{* * * * *}$ \\
\hline Explained variance of & $72 \%$ & $26 \%$ & $21 \%$ \\
\hline Planning & $18 \%$ & $21 \%$ & $38 \%$ \\
\hline Recovery self-efficacy & $13 \%$ & $6 \%$ & $10 \%$ \\
\hline Physical exercise & $25 \%$ & $40 \%$ & $33 \%$ \\
\hline
\end{tabular}

Note. Study 1: cardiac rehabilitation patients (German); Study 2: cardiac rehabilitation patients (Polish); Study 3: orthopedic rehabilitation patients (German).

${ }^{*} p \leq .10 .{ }^{*} p<.05 . *{ }^{* *} p<.01 .001$. cardiac event. It combines medically supervised exercises with education regarding reduction of risk factors associated with coronary heart disease.

Intention, risk perception, outcome expectancies, and action self-efficacy were measured at Time 1. Planning and recovery self-efficacy were measured at Time 2 , and physical activity at Time 3. For item examples, means, standard deviations, and internal consistencies, see Table 1. For intercorrelations between all variables, see Table 2 .

\section{Results}

The hypothesized model fit the data (see Table 3 ). Figure 2 displays the parameter estimates (standardized solution). From a check of the residuals, it appeared that the unique variances associated with indicators included in the model should not be correlated. The standardized loadings of the factors were moderate or high. Excluding risk perception, all manifest variables loaded significantly, $p<.05$, on their hypothesized factors. Planning and recovery self-efficacy emerged as mediators for the action self-efficacy-behavior relation and the intention-behavior relation, respectively, as hypothesized. Six percent of variance of the recovery self-efficacy has been accounted for by action self-efficacy, attesting to the discriminant validity of the two constructs. Of the planning variance, $21 \%$ has been accounted for by intention and recovery self-efficacy, and $39 \%$ of the physical activity variance has been explained jointly by planning and recovery self-efficacy. Inclusion of past behavior in the model (see Tables 3 and 4) did not make a substantial difference in terms of model fit and structural coefficients. 


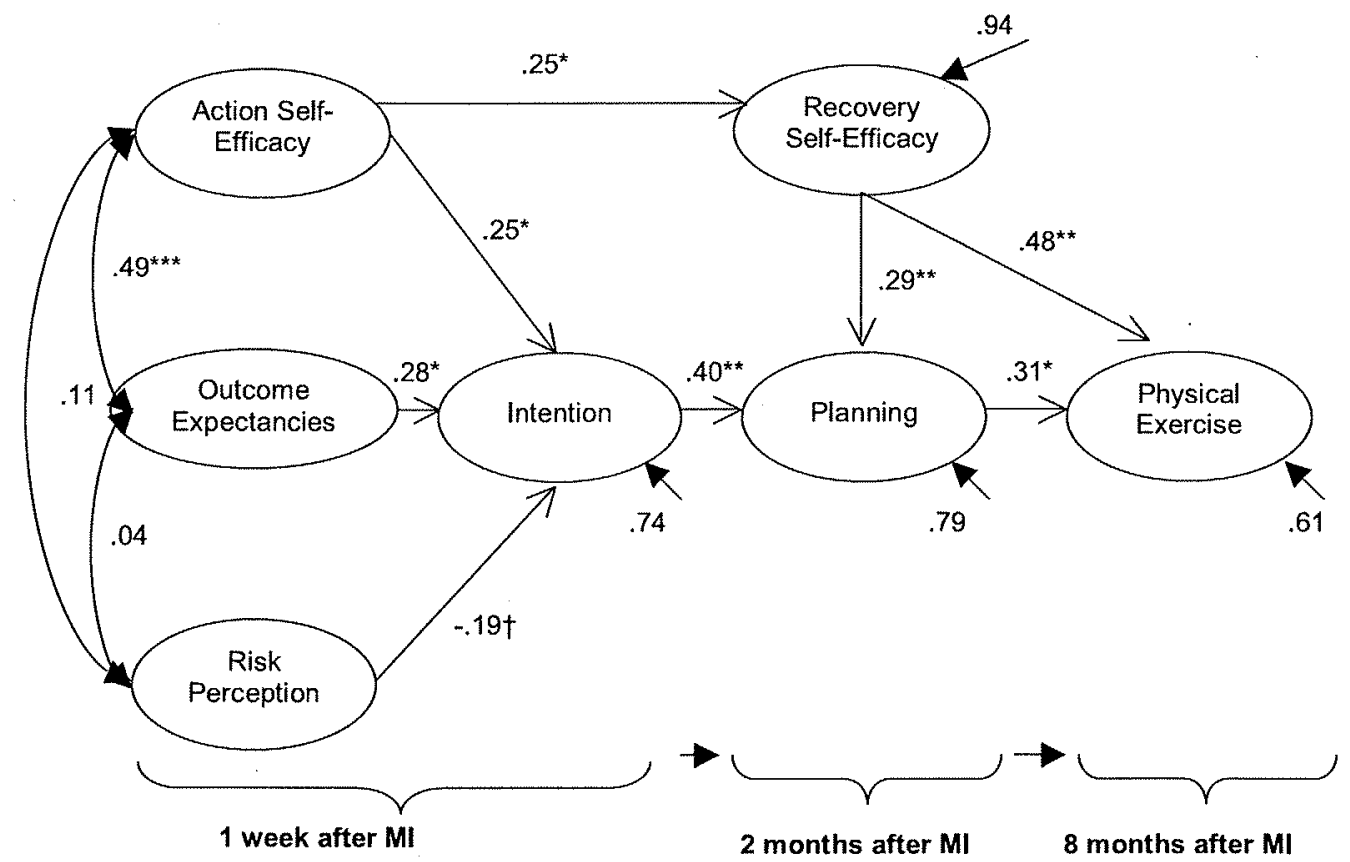

Figure 2. Prediction model for cardiac patients in Study II $(N=114)$. MI = myocardial infarction. ${ }^{\dagger} p<.10$. ${ }^{*} p<.05{ }^{* * *} p<.01$.

\section{Study 3: Predicting Physical Exercise Adherence in Orthopedic Rehabilitation Over a Time Span of 12 Months}

The third study examines exercise adherence in a sample of orthopedic rehabilitation patients in Germany. The study had a number of different aims that are presented elsewhere (Lippke et al., 2004; Ziegelmann et al., 2006). The following analysis applies the HAPA model to a longitudinal data set with three points in time, covering a 12-month period. The research question is the same as in the other two studies mentioned above.

\section{Method}

Participants. Six hundred and thirty-seven persons with orthopedic ailments, such as back pain (51\%), disc disorders $(39 \%)$, joint conditions (19\%), and injuries (10\%), were recruited during outpatient orthopedic rehabilitation. The final longitudinal sample consisted of 368 participants, aged 18 to 80 years, $M=47.4, S D=$ $11.7,38 \%$ of whom were men. The majority of the respondents $(73 \%)$ were married or living with a partner; $45 \%$ had completed high-school education, and $26 \%$ had a university degree.

To check the dropout, patients who discontinued participating in the study at Time 2 or Time 3 were compared with those who took part in all waves of data collection. Those who took part in all measurement points were significantly older, $F(1,635)=9.53$, $p<.05$. Otherwise, participants differed neither in gender, $\chi^{2}(1, N$ $=637)=0.20, n s$; education, $\chi^{2}(1, N=637)=2.94, n s ; \mathrm{BMI}$, $F(1,635)=2.07, n s ;$ risk perception, $F(1,635)=2.25, n s ;$ outcome expectancies, $F(1,635)=0.74, n s$; action self-efficacy, $F(1,635)=0.87, n s$, intention, $F(1,635)=0.02$, ns; planning,
$F(1,635)=1.28, n s ;$ and recovery self-efficacy, $F(1,635)=$ $2.42, n s$.

Procedure. Participants were approached by members of the research team (psychologists or rehabilitation specialists), informed about the purpose and design of the study, and asked to participate on a voluntary basis. Time 1 took place at the start of rehabilitation, Time 2 took place 6 months after discharge, and Time 3 took place 12 months after discharge. The short-term (3-week) rehabilitation program consisted of physical exercise therapy and education about pursuing a healthy lifestyle.

Measures. Risk perception, outcome expectancies, and action self-efficacy were measured at Time 1 . Intention, planning, and recovery self-efficacy were measured at Time 2 . In addition, physical activity was assessed for baseline and at Time 3 . The physical activity measure was validated in previous research (Ziegelmann \& Lippke, 2007). For item examples, means, standard deviations, and internal consistencies, see Table 1. For intercorrelations between all variables, see Table 2 .

\section{Results}

The hypothesized model fit the data (see Table 3 ), although not optimally. Figure 3 displays the parameter estimates (standardized solution). Excluding risk perception and outcome expectancies, all hypothesized paths were significant, $p<.01$. Planning and recovery self-efficacy accounted for a substantial amount of variance in behavior. Eight percent of variance of the recovery self-efficacy was accounted for by action self-efficacy, attesting to the discriminant validity of the two constructs. Of the planning variance, $39 \%$ was accounted for by intention and recovery self-efficacy, and 


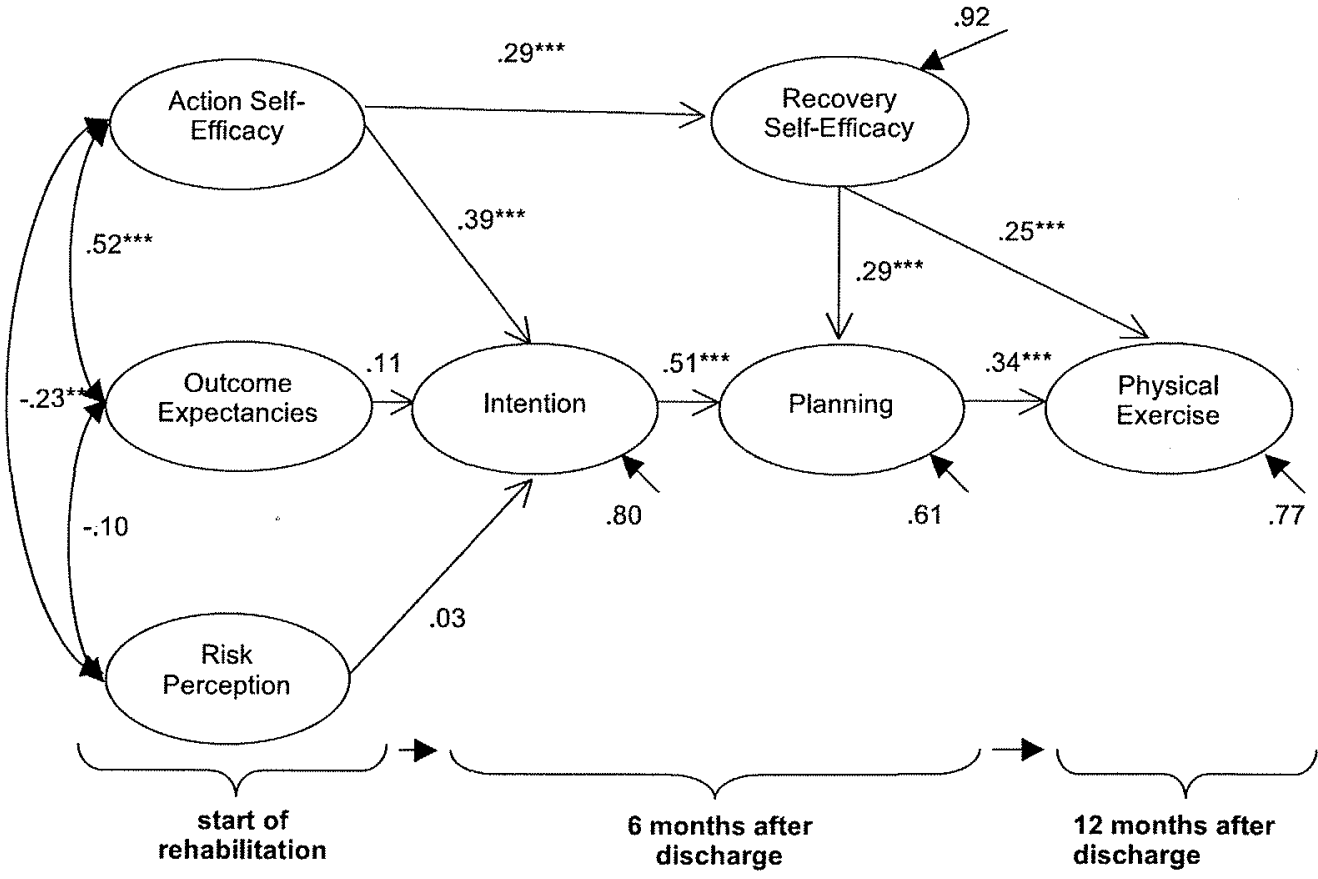

Figure 3. Prediction model for orthopedic patients in Study III $(N=368) .{ }^{*} p<.10 .{ }^{*} p<.05 .{ }^{* * *} p<.01 .{ }^{* n * *} p$ $<.001$

$23 \%$ of the physical activity variance was explained jointly by planning and recovery self-efficacy. Inclusion of past behavior in the model (see Tables 3 and 4 ) did not make a substantial difference in terms of model fit and structural coefficients.

\section{General Discussion}

Three studies on the prediction of the level of physical exercise have been presented that focus on long-term adherence covering time spans of 4 months (Study 1), 8 months (Study 2), and 1 year (Study 3). Samples from two countries were chosen that included patients enrolled in either cardiac or orthopedic rehabilitation. In all three studies, the HAPA model fit the data, suggesting that the selected set of variables and the specified order may be appropriate to describe such data, although a technically good model fit does not exclude the possibility that alternative models fit the data as well.

Planning and recovery self-efficacy were specified as proximal predictors of behavior, and planning was supposed to bridge the gap between intentions and behavior. Results suggest that these constructs indeed serve their purpose, which is in line with previous research, indicating that self-reported planning mediates between intention and behavior (Jones, Abraham, Harris, Schulz, \& Chrispin, 2001). Findings of the three studies differ, however, in some respects. Different amounts of variance were accounted for by the predictors. Of the physical exercise variance, $15 \%$ to $39 \%$ were explained, whereas of the planning variance, $18 \%$ to $39 \%$ were explained. However, the overall pattern of relations appeared to be similar across studies. The amount of exercise variance accounted for in the present models is not much different from the one in other models (Norman \& Conner, 2005). However, this has to be judged in terms of the time span between predictor and criterion, given the fact that the present studies include unusually long time spans, namely 4, 8, and 12 months in Studies 1,2, and 3 , respectively.

The fact that risk perception was not significantly related to any of the variables under study, as opposed to the other socialcognitive variables, raises general questions about how health behaviors can be predicted and modified. The fear appeal approach, a traditional intervention strategy, focuses on using risk communication to let people recognize how much they are at risk for illness or injury, but it has not been very successful (Weinstein, 2003). The present findings would emphasize a different strategy by making rehabilitation patients aware of their resources, that is, their planning skills and self-regulation strategies to change a refractory behavior. Patients should learn how to translate their intentions into action. Resource communication would address strategic planning and optimistic self-beliefs, which might be more appropriate than risk communication. Furthermore, interventions should be tailored to fit the needs of the recipients. For those who are in the preintentional (motivational) phase, it would be most promising to improve action self-efficacy and outcome expectancies, whereas for their counterparts in the postintentional (volitional) phase it would be more suitable to focus on planning and recovery self-efficacy.

The present findings contribute to our understanding of some mechanisms that are involved in health behavior change. The traditional view, namely that intentions are the best predictors of behavior (Fishbein \& Ajzen, 1975), becomes increasingly ques- 
tionable in the light of findings like the present ones (see also Norman \& Conner, 2005). Postintentional constructs allow for a more direct prediction of behavior. The present data emphasize that planning and recovery self-efficacy appear to be suitable direct predictors of physical exercise adherence in rehabilitation patients. This is theoretically meaningful because intenders face unforeseen barriers and are challenged by temptations. One's confidence in being able to meet such demands, together with concrete planning of when, where, and how to initiate action, can help individuals to translate their intentions into action.

A limitation refers to the measurement of physical activity. The criterion variable is self-reported, and there is no direct possibility to examine the validity of these self-reports. However, there is evidence for the validity of physical activity self-reports (Miller, Freedson, \& Kline, 1994). Not all psychometric properties were ideal, which is, however, in line with the majority of measures and studies on this topic (Sallis \& Saelens, 2000). In particular, some of the internal consistencies were low, which can be regarded as an implication of parsimony because most scales included only three to five items. This can result in low alphas, but not necessarily in poor reliability if scales are unidimensional. Alpha represents the lower bound of reliability (Cortina, 1993). Extending the length of scales would be in conflict with the aim of parsimony. Future research with these unidimensional scales should target this issue.

Despite these limitations, the three studies presented here make a substantial contribution to the literature on predicting and explaining health behavior because their results are consistent across different measures, samples, languages, rehabilitation settings, and time spans. Also, they replicate an earlier finding on breast selfexamination (Luszczynska \& Schwarzer, 2003), which points to the applicability of the HAPA model across different behaviors. The HAPA model outlines the complex mechanisms that operate when individuals become motivated to change their habits, when they adopt and maintain a new behavior, and when they attempt to resist temptations and recover from setbacks. The model is assumed to be applicable to all health-compromising and healthenhancing behaviors.

\section{References}

Abraham, C., \& Sheeran, P. (2000). Understanding and changing health behavior: From health beliefs to self-regulation. In P. Norman, C Abraham, \& M. Conner (Eds.), Understanding and changing health behavior (pp. 3-24). Amsterdam: Harwood.

Ajzen, I. (1991). The theory of planned behavior. Organizational Behavior and Human Decision Processes, 50, 179-211.

Arbuckle, J. L. (2003). Amos 5.0 user guide. Chicago: Small Waters.

Armitage, C. J., \& Conner, M. (2000). Social cognition models and health behaviour. Psychology and Health, 15, 173-189.

Armitage, C. J., \& Conner, M. (2001). Efficacy of the theory of planned behaviour: A meta-analytic review. British Joumal of Social Psychology, 40, 471-499.

Bandura, A. (1986). Social foundations of thought and action. Englewood Cliffs, NJ: Prentice Hall.

Bandura, A. (1997). Self-efficacy: The exercise of control. New York: Freeman.

Bandura, A. (2000). Cultivate self-efficacy for personal and organizational effectiveness. In E. A. Locke (Ed.), The Blackwell handbook of principles of organizational behavior (pp. 120-136). Oxford, England: Blackwell.
Booth, M. L. (2000). Assessment of physical activity: An international perspective. Research Quarterly for Exercise and Sport, 71, 114-120.

Conner, M., \& Norman, P. (Eds.). (2005). Predicting health behavior: Research and practice with social cognition models (2nd ed.). Buckingham, England: Open University Press.

Cortina, J. M. (1993). What is coefficient alpha? An examination of theory and applications. Journal of Applied Psychology, 78, 98-104.

Fishbein, M., \& Ajzen, I. (1975). Belief, attitude, intention, and behavior: An introduction to theory and research. Reading, MA: Addison-Wesley.

Gollwitzer, P. M. (1993). Goal achievement: The role of intentions. In W. Stroebe \& M. Hewstone (Eds.), European review of social psychology (Vol. 4, pp. 141-185). Chichester, England: Wiley.

Gollwitzer, P. M. (1999). Implementation intentions: Strong effects of simple plans. American Psychologist, 54, 493-503.

Gollwitzer, P. M., \& Sheeran, P. (2006). Implementation intentions and goal achievement: A meta-analysis of effects and processes. Advances in Experimental Social Psychology, 38, 69-119.

Heckhausen, H. (1991). Motivation and action. Berlin, Germany: Springer.

Hu, L., \& Bentler, P. M. (1995). Evaluating model fit. In R. H. Hoyle (Ed.), Structural equation modeling. Concepts, issues, and applications (pp. 76-99). Thousand Oaks, CA: Sage.

Jones, F., Abraham, C., Harris, P., Schulz, J., \& Chrispin, C. (2001). From knowledge to action regulation: Modeling the cognitive prerequisites of sun screen use in Australian and UK samples. Psychology and Health. 16, 19l-206.

Leventhal, H., Singer, R., \& Jones, S. (1965). Effects of fear and specificity of recommendation upon attitudes and behavior. Journal of Personality and Social Psychology, 2, 20-29.

Lippke, S., Ziegelmann, J. P., \& Schwarzer, R. (2004). Initiation and maintenance of physical exercise: Stage-specific effects of a planning intervention. Research in Sports Medicine, 12, 221-240.

Luszczynska, A. (2006). Effects of an implementation intention intervention on physical activity after $\mathrm{Ml}$ are mediated by cognitive processes, change in forming action plans. Social Science and Medicine, 62, 900908.

Luszczynska, A., \& Schwarzer, R. (2003). Planning and self-efficacy in the adoption and maintenance of breast self-examination: A longitudinal study on self-regulatory cognitions. Psychology and Health, 18,93-108.

Luszczynska, A., Sobczyk, A., \& Abraham, C. (2007). Planning to lose weight: RCT of an implementation intention prompt to enhance weight reduction among overweight and obese women. Health Psychology, 26, $507-512$.

Luszczynska, A., \& Sutton, S. (2006). Physical activity after cardia rehabilitation: Evidence that different types of self-efficacy are important in maintainers and relapsers. Rehabilitation Psychology, 51, 314-321.

Maddux, J. E., \& Rogers, R. W. (1983). Protection motivation and selfefficacy: A revised theory of fear appeals and attitude change, Journal of Experimental Social Psychology, 19, 469-479.

Marlatt, G. A., Baer, J. S., \& Quigley, L. A. (1995). Self-efficacy and addictive behavior. In A. Bandura (Ed.), Self-efficacy in changing societies (pp. 289-315). New York: Cambridge University Press.

Miller, D. J., Freedson, P. S., \& Kline, G. M. (1994). Comparison of activity levels using the Caltrac accelerometer and five questionnaires. Medicine and Science in Sports and Exercise, 26, 376-382.

Norman, P., \& Conner, M. (2005). The Theory of Planned Behavior and exercise: Evidence for the mediating and moderating roles of planning on intention-behavior relationships. Journal of Sport and Exercise Psy. chology, 27, 488-504.

Rodgers, W. M., Hall, C. R., Blanchard, C. M., McAuley, E., \& Munroe, K. J. (2002). Task and scheduling self-efficacy as predictors of exercise behaviour. Psychology and Health, 27, 405-416.

Rodgers, W. M., \& Sullivan, M. J. L. (2001). Task, coping and scheduling self-efficacy in relation to frequency of physical activity. Joumal of Applied Social Psychology, 31, 741-753. 
Rutter, D., \& Quine, L. (2002). Social cognition models and changing health behaviours. In D. Rutter \& L. Quine (Eds.), Changing health behaviour: Intervention and research with social cognition models (pp. 1-27). Buckingham, England: Open University Press.

Sallis, J. F., \& Saelens, B. E. (2000). Assessment of physical activity by self-reports: Status, limitations, and future directions. Research Quarterly for Exercise and Sport, 71, 1-14.

Scholz, U., Sniehotta, F. F., Burkert, S., \& Schwarzer, R. (in press). Increasing physical exercise levels: Age-specific benefits of planning. Journal of Aging and Health.

Scholz, U., Sniehotta, F. F., \& Schwarzer, R. (2005). Predicting physical exercise in cardiac rehabilitation: The role of phase-specific self-efficacy beliefs. Joumal of Sport \& Exercise Psychology, 27, 135-151.

Schüz, B., Sniehotta, F. F., \& Schwarzer, R. (2007). Stage-specific effects of an action control intervention on dental flossing. Health Education Research, 22, 332-341.

Schwarzer, R. (1992). Self-efficacy in the adoption and maintenance of health behaviors: Theoretical approaches and a new model. In $R$. Schwarzer (Ed.), Self-efficacy: Thought control of action (pp. 217-243). Washington, DC: Hemisphere.

Schwarzer, R., \& Renner, B. (2000). Social-cognitive predictors of health behavior: Action self-efficacy and coping self-efficacy. Health Psychol ogy, 19, 487-495.

Sheeran, P., Milne, S., Webb, T. L., \& Gollwitzer, P. M. (2005). Implementation intentions and health behaviors. In M. Conner \& P. Norman (Eds.), Predicting health behaviour: Research and practice with social cognition models (2nd ed., pp. 276-323). Buckingham, England: Open University Press.

Sniehotta, F. F., Scholz, U., \& Schwarzer, R. (2005). Bridging the intention-behaviour gap: Planning, self-efficacy, and action control in the adoption and maintenance of physical exercise. Psychology and Health, 20, 143-160.

Sutton, S. (1998). Predicting and explaining intentions and behavior: How well are we doing? Journal of Applied Social Psychology, 28, 1317 1338.

Weinstein, N. D. (1993). Testing four competing theories of healthprotective behavior. Health Psychology, 12, 324-333.

Weinstein, N. D. (2003). Exploring the links between risk perceptions and preventive health behavior. In J. Suls \& K. Wallston (Eds.), Social psychological foundations of health and illness (pp. 22-53). Oxford, England: Blackwell.

Weinstein, N. D. (2007). Misleading tests of health behavior theories. Annals of Behavioral Medicine, 33, 1-10.

Ziegelmann, J. P., \& Lippke, S. (2007). Planning and strategy use in health behavior change: A life span view. International Journal of Behavioral Medicine, 14, 30-39.

Ziegelmann, J. P., Lippke, S., \& Schwarzer, R. (2006). Adoption and maintenance of physical activity: Planning interventions in young, middle-aged, and older adults. Psychology and Health, 21, 145-163.

Ziegelmann, J, P., Luszczynska, A., Lippke, S., \& Schwarzer, R. (2007) Are goal intentions or implementation intentions better predictors of health behavior? A longitudinal study in orthopedic rehabilitation. Rehabilitation Psychology, 52, 97-102. 